University of Wollongong

Research Online

Faculty of Engineering - Papers (Archive)

Faculty of Engineering and Information

Sciences

$1-1-2008$

\title{
Chemical synthesis, characterisation and gas sensing performance of copper oxide nanoribbons
}

Xing L. Gou

University of Wollongong, xinglong@uow.edu.au

Guoxiu Wang

University of Wollongong, gwang@uow.edu.au

Juan Yang

University of Wollongong

Jinsoo Park

University of Wollongong, jp450@uow.edu.au

David Wexler

University of Wollongong, david_wexler@uow.edu.au

Follow this and additional works at: https://ro.uow.edu.au/engpapers

Part of the Engineering Commons

https://ro.uow.edu.au/engpapers/4240

\section{Recommended Citation}

Gou, Xing L.; Wang, Guoxiu; Yang, Juan; Park, Jinsoo; and Wexler, David: Chemical synthesis, characterisation and gas sensing performance of copper oxide nanoribbons 2008, 965-969.

https://ro.uow.edu.au/engpapers/4240

Research Online is the open access institutional repository for the University of Wollongong. For further information contact the UOW Library: research-pubs@uow.edu.au 


\title{
Chemical synthesis, characterisation and gas sensing performance of copper oxide nanoribbons $\uparrow$
}

\author{
Xinglong Gou, Guoxiu Wang, “ Juan Yang, Jinsoo Park and David Wexler \\ Received 30th October 2007, Accepted 2nd January 2008 \\ First published as an Advance Article on the web 24th January 2008 \\ DOI: $10.1039 / \mathrm{b} 716745 \mathrm{~h}$
}

Single crystalline copper oxide nanoribbons were synthesized via a surfactant-assisted hydrothermal route. The resulting $\mathrm{CuO}$ nanoribbons contain substantial amounts of nanorings and nanoloops. High resolution TEM analysis identified $\mathrm{CuO}$ nanoribbons growing along the [010] direction. $\mathrm{CuO}$

nanoribbons exhibited excellent sensing performance towards formaldehyde and ethanol vapours with rapid response and high sensitivity at low operating temperatures. We found that the loading of a small amount of $\mathrm{Au}$ or Pt nanoparticles on the surface of $\mathrm{CuO}$ nanoribbons can effectively enhance and functionalize the gas sensing performance of $\mathrm{CuO}$ nanoribbons.

\section{Introduction}

One-dimensional nanostructures such as nanotubes, nanowires, nanorods and nanoribbons have been extensively investigated worldwide, ${ }^{1-4}$ because they have many potential technological applications, including nanoelectronics, nanophotonics, nanocomputing and nanoscale bio and chemical sensing. Chemical sensors play an important role in the areas of emissions control, environmental protection, public safety, and human health. ${ }^{5-7}$ Much more public concern today than ever before over the serious environmental issue are further promoting the development of sensors with both high sensitivity and rapid response. In addition to in-depth exploration of gas sensing mechanisms ${ }^{8}$ and innovative sensor device design, ${ }^{9}$ a variety of novel gas sensors based on metal oxide one-dimensional (ID) nanostructures, such as $\mathrm{SnO}_{2},{ }^{10} \mathrm{In}_{2} \mathrm{O}_{3},{ }^{11} \mathrm{Fe}_{2} \mathrm{O}_{3},{ }^{12} \mathrm{WO}_{3},{ }^{5} \mathrm{~V}_{2} \mathrm{O}_{5},{ }^{13} \mathrm{ZnO},{ }^{14}$ and $\mathrm{TiO}_{2}{ }^{15}$ etc. have been successfully fabricated and intensively investigated. It has been well documented that the large surfaceto-volume ratios of nanobelts or nanoribbons, along with the congruence of the carrier screening length with their lateral dimensions, make them excellent candidates for gas sensing applications. ${ }^{16,17}$ It was also found that surface doping of n-type metal oxide semiconductors with catalytic metals, such as platinum, gold, palladium, and iridium can further improve the sensitivity, reduce the response time and operation temperature, and even change the selectivity pattern. ${ }^{18-20}$ However, to date most efforts in the field of metal oxide gas sensors have been devoted to n-type semiconductors, while the sensing properties of the p-type one-dimensional metal oxide semiconductors have scarcely been investigated.

As an important p-type semiconductor, cupric oxide $(\mathrm{CuO})$ has been extensively studied due to its diverse applications,

School of Mechanical, Materials and Mechatronic Engineering, and Institute for Siperconducting and Electronic Materials, University of Wollongong, Wollongong, NSW 2522, Australia. E-mail: glang@uw. cdu:au: Fox: +6124221 3112; Tel: +61242215726

$\uparrow$ Electronic supplementary information (ESI) available: TGA curve of CuO nanoribbons, FESEM image of CUO nanoplates. and TEM images of Au- and Pt-loaded CuO nanoribbons. See DOI: 10.1039/b716745h such as in gas sensors, catalysis, batteries, high critical temperature superconductors, solar energy conversion, and field emission emitters. ${ }^{21-23}$ For these potential applications, $\mathrm{CuO}$ micro- or nanó-structures with various morphologies have been synthesized. ${ }^{24-28}$ Nevertheless, very little work has been directed towards fabricating gas sensors based on $1 \mathrm{D} \mathrm{CuO} \mathrm{nano-}$ structures, and there are no reports on the gas sensing properties of $\mathrm{CuO}$ nanoribbons. Herein, we report the chemical synthesis and the gas sensing properties of p-type $\mathrm{CuO}$ nanoribbons with and without noble metal additives towards formaldehyde and ethanol gases for the first time. We show that the p-type semiconductor gas sensors based on $\mathrm{CuO}$ nanoribbons have rapid response and high sensitivity to very low concentrations of formaldehyde and ethanol gases at low operating temperatures, and that their sensing performances can be further enhanced by functionalizing the $\mathrm{CuO}$ nanoribbons with small quantities of $\mathrm{Pt}$ or $\mathrm{Au}$ nanoparticles.

\section{Experimental}

$\mathrm{CuO}$ nanoribbons were synthesized from the hydrothermal reaction between $\mathrm{CuSO}_{4}$ and $\mathrm{NaOH}$ in the presence of an anion surfactant sodium dodecylbenzenesulfonate (SDBS). In a typical procedure, $10 \mathrm{~mL}$ of $0.1 \mathrm{M}$ sodium dodecylbenzenesulfonate (SDBS) was dropped into $10 \mathrm{~mL}$ of $0.1 \mathrm{M} \mathrm{CuSO}_{4}$ solution with continuous stirring. Subsequently, $10 \mathrm{~mL}$ of $6 \mathrm{M} \mathrm{NaOH}$ solution was added dropwise into the above suspension. After stirring for another $10 \mathrm{~min}$, the mixture was hydrothermally treated at $120{ }^{\circ} \mathrm{C}$ for $10 \mathrm{~h}$. The black product was collected and washed with distilled water and absolute ethanol, and finally dried under a vacuum at $60^{\circ} \mathrm{C}$ for $4 \mathrm{~h}$.

Functionalization of the $\mathrm{CuO}$ nanoribbons with $\mathrm{Pt}$ and $\mathrm{Au}$ was carried out through a wet-chemical reduction method. Briefly, the as-prepared $\mathrm{CuO}$ nanoribbons were ultrasonically dispersed in $20 \mathrm{~mL}$ of $\mathrm{H}_{2} \mathrm{O}$, to which a given amount of $\mathrm{H}_{2} \mathrm{PtCl}_{6}$ or $\mathrm{HAuCl}_{4}(1 \%$ to $\mathrm{CuO}$ in molar ratio) and $\mathrm{L}$-ascorbic acid solution was added sequentially. After the above mixture was heated at $60{ }^{\circ} \mathrm{C}$ for $15 \mathrm{~min}$ under continuous stirring, the products were collected in the same way as for the pristine nanoribbons. 
The as-prepared samples were characterized by X-ray diffraction (XRD, Cu K $\alpha$ radiation, Philips 1730), field emission scanning electron microscopy (FESEM, JEOL 6700F) equipped with energy-dispersive X-ray spectroscopy (EDS), transmission electron microscopy (TEM) and high-resolution TEM (HRTEM, JEOL 2011).

Gas sensing measurements were carried out on a computercontrolled WS-30A system. The structure, fabrication and testing principle of our gas sensors based on the as-prepared $\mathrm{CuO}$ nanoribbons is similar to that for $\mathrm{Fe}_{2} \mathrm{O}_{3}$ nanotubes. ${ }^{8}$ For comparison, the other two types of gas sensors using the commercial $\mathrm{CuO}$ powders $(<5 \mu \mathrm{m})$ and the nanoplates, which were synthesized through a procedure similar to that for $\mathrm{CuO}$ nanoribbons but replacing SDBS with sodium citrate, were also fabricated and tested.

\section{Results and discussion}

The morphology of the as-synthesized $\mathrm{CuO}$ products was observed via field emission scanning electron microscope (FESEM) and is shown in Fig. 1(a). The high yield of $\mathrm{CuO}$ nanoribbons has been observed by SEM. The nanoribbons have varied widths and lengths extending for tens of micrometres. The chemical composition of the nanoribbons was analysed by energy dispersive X-ray spectroscopy (EDS) and is shown in Fig, 1(b)), which revealed that the nanoribbons are only composed of $\mathrm{Cu}$ and $\mathrm{O}$, and the atomic ratio of $\mathrm{Cu}$ to $\mathrm{O}$ was very close to $1: 1$, in agreement with the stoichiometric proportion of $\mathrm{CuO}$. The as-prepared $\mathrm{CuO}$ nanoribbons contain $2 \mathrm{wt} \%$ SDBS surfactant, which has been determined by thermogravimetric analysis (TGA, Fig. S1†).

The phase purity of nanoribbons was determined by powder $X$-ray diffraction (XRD) as shown in Fig. 2. All the diffraction peaks can be readily indexed to the monoclinic symmetry of $\mathrm{CuO}$ (space group $C 2 / c, a=4.684 \AA, b=3.425 \AA, c=5.129$ $\AA, \beta=99.47^{\circ}$; ICDD-JCPDS file no. 05-0661). The broadening
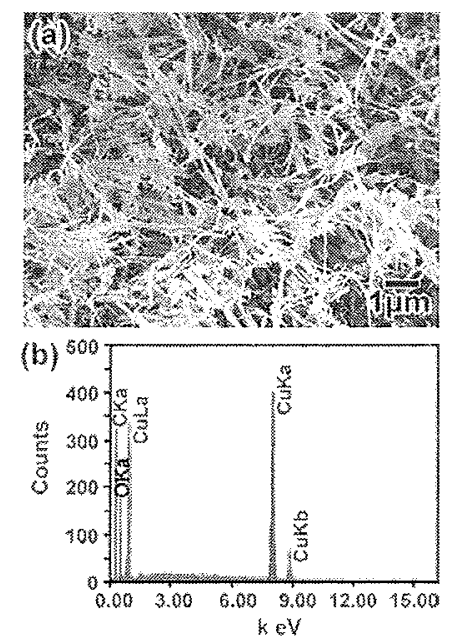

Fig. 1 (a) FESEM image shows the morphology of the CuO product; (b) EDS pattern reveals that the $\mathrm{CuO}$ products are composed of $\mathrm{Cu}$ and $O$ with a ratio of $1: 1.08$. The signal of carbon came from the carbon conducting tape on which $\mathrm{CuO}$ samples were stuck.

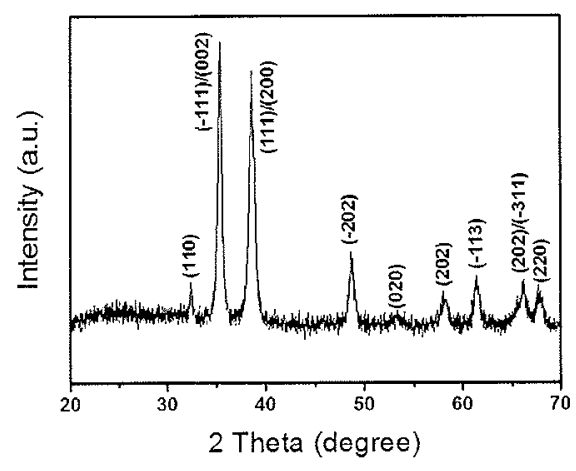

Fig. 2 XRD pattern of the as-synthesized CuO nanoribbon.

of all the recorded peaks in the XRD pattern indicates that the component crystallites are of nanoscale character. No other impurities were detected by XRD analysis, indicating the phase purity of the $\mathrm{CuO}$ nanoribbons, which was consistent with the EDS analysis result.

The micromorphology and erystallographic structure of the $\mathrm{CuO}$ nanoribbons were further analysed by transmission electron microscopy (TEM) and high resolution TEM (HRTEM). Fig. 3(a) shows a low magnification TEM image of CuO nanoribbons, revealing the abundant ribbon-like ID nanostructures.
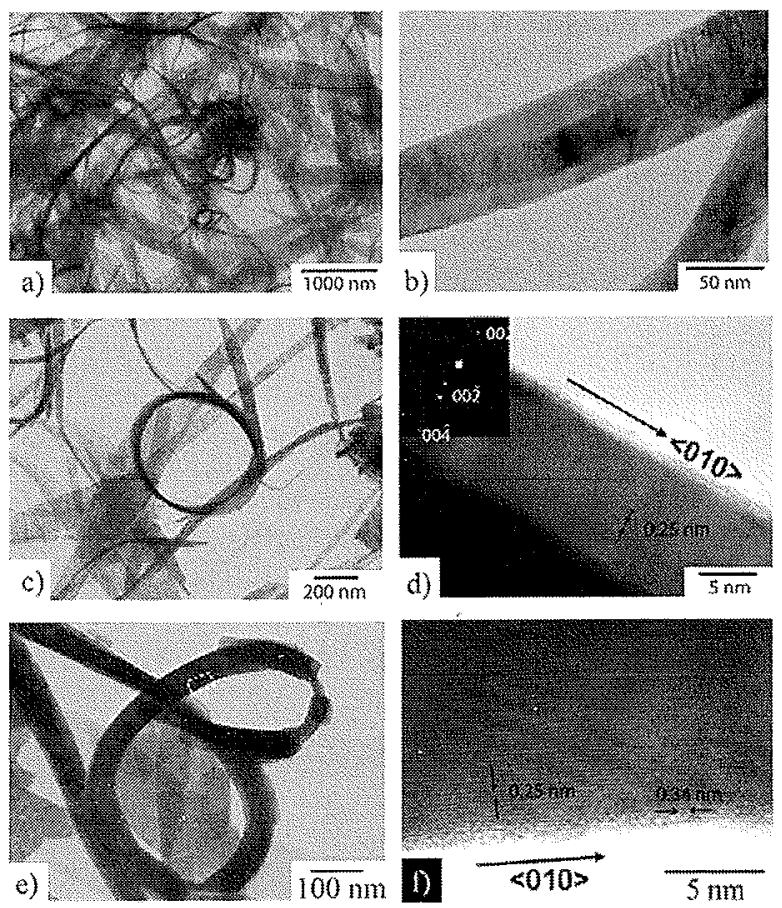

Fig. 3 Bright field TEM images showing microstructural features of $\mathrm{CuO}$ nanoribbons. (a) Tangled nanoribbons at low magnification; (b) overlapping thin and thick nanoribbons; (c) CuO nanoring; (d) HRTEM image and selected area diffraction pattern (inset) showing (002) planes parallel to the growth direction of nanoribbons; (e) nanoring loops; ( $f$ ) HRTEM image of region in (e) indicated by rectangle, interplanar spacings consistent with (002) parallel to ribbon long axis and (010) plane perpendicular to long axis. 
The width of the nanoribbons is in the range of $30-100 \mathrm{~nm}$ and the thickness is about $2-8 \mathrm{~nm}$. Among the nanoribbons, some are straight with a flat lateral face along the length direction, while the others are bent and inter-twisted, implying that the nanoribbons are highly flexible. Straight nanoribbons were frequently joined and overlapped in parallel on the flat sides, even with nanoribbons of different thickness, as shown in Fig. 3(b), indicating strong attractive forces between the fiat sides of parallel nanoribbons. The bending contour of CuO nanoribbons is clearly illustrated under an electron beam. We also observed $\mathrm{CuO}$ nanoribbon rings (Fig. 3(c)). Those nanorings were formed by bending of 1 or 2 nanoribbons. Complex nanoloops were observed (Fig. 3(e)), which were formed by several nanoribbons joined in parallel on the flat sides and then bent into loops or looped segments. Fig. 3(d) and (f) further show the HRTEM images of a $\mathrm{CUO}$ nanoribbon and a nanoloop respectively. Combined with selected area electron diffraction (SAED) (the inset in Fig. 3(d)), it revealed the same growth direction for the nanoribbons, nanorings and nanoloops, i.e. along the [010] direction. Both HRTEM and SAED analyses confirmed the single crystalline nature of the as-grown $\mathrm{CuO}$ nanoribbons, nanorings and nanoloops.

During the synthesis of $\mathrm{CuO}$ 1D nanostructures, sodium dodecylbenzenesulfonate surfactant played an important role. Without addition of SDBS, or on replacing SDBS with other surfactants such as polyvinyl alcohol, polyethylene glycol, polyvinylpyrrolidone or cetyltrimethylammonium bromide, neither nanoribbons nor nanorings were obtained. When the coordination agent sodium citrate was introduced instead of SDBS, we obtained $\mathrm{CuO}$ nanoplates (Fig. S2†).

$\mathrm{Pt}$ and $\mathrm{Au}$ were loaded on the $\mathrm{CuO}$ nanoribbons by chemically reducing $\mathrm{H}_{2} \mathrm{PtCl}_{6}$ or $\mathrm{HAuCl}_{4}$ with L-ascorbic acid as the reducing agent. Fig. 4(a) and (b) show the SEM images of Pt- and Au-loaded samples, respectively. We noticed that the chemical loading with Pt or Au does not change the morphology

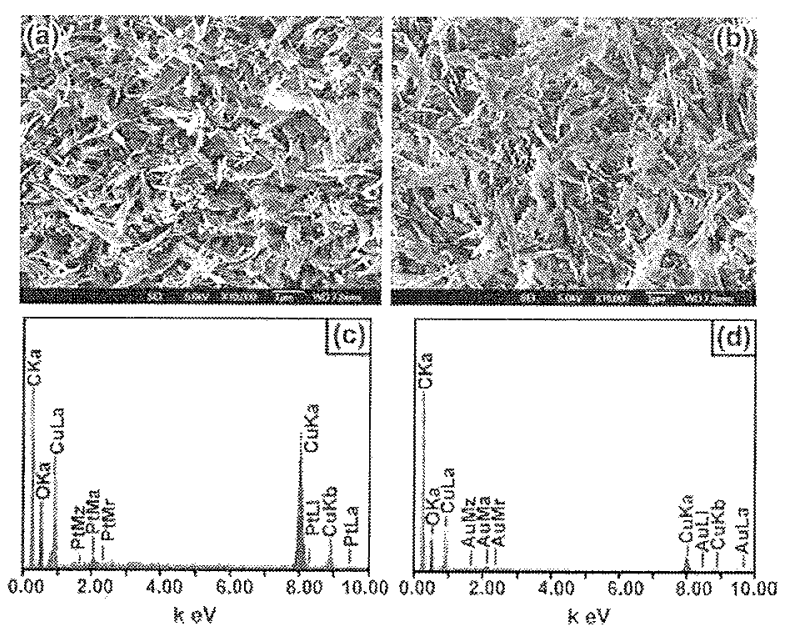

Fig. 4 ( $a, b)$ SEM image of the Pt-and Au-loaded samples, respectively indicating the loading of noble metals did not change the morphology of CuO nanoribbons. (c, d) EDS pattern of the Pt- and At-loaded samples, indicating the content of Pt and $A u$ is $0.50 \mathrm{~atm} \%$ and $0.78 \mathrm{~atm} \%$, respectively. or shape of the CuO nanoribbons. The XRD patterns of the Pt-and Au-loaded samples (not shown here) are in essence the same as that of the pristine $\mathrm{CuO}$ nanoribbons. No Pt or $\mathrm{Au}$ diffraction peaks have been detected due to their trace contents. However, the catalytic metals $\mathrm{Pt}$ and $\mathrm{Au}$ were quantitatively detected by EDS analysis and are shown in Fig. 4(c) and (d), respectively. Their contents were about $0.50 \mathrm{~atm} \%$ and $0.78 \mathrm{~atm} \%$ for the Pt-loaded sample ( $\mathrm{Pt}-\mathrm{CuO}$ nanoribbons) and the Au-loaded sample (Au-CuO nanoribbons), respectively. TEM, HRTEM and EDS analyses were further performed on $\mathrm{Au}$ - and Pt-loaded $\mathrm{CuO}$ nanoribbons, clearly showing the presence of $\mathrm{Au}$ and Pt nanoparticles (Fig. S3 and S4 $^{\text {). }}$.

Combining the unique characteristics of $\mathrm{CuO}$ nanoribbons with the catalytic role of noble metals, we expected that the as-synthesized $\mathrm{CuO}$ nanoribbons (with or without noble metal additives) would be promising candidates for fabricating high performance gas sensors to detect some chemical contaminants and dangerous gases. Among the common environmental pollutants, formaldehyde (HCHO) is a known carcinogen and toxic to human health. It commonly exists in building materials, pathology laboratories, industrial chemical processes and the combustion gas of organic materials. Thus, effective $\mathrm{HCHO}$ gas sensors are of great importance and much needed for both environmental protection and human health. Meanwhile, ethanol sensors with rapid response and high sensitivity and stability are urgently demanded in the biomedical, chemical and food industries, especially in wine quality monitoring and breath analyzers. For this reason we fabricated the p-type semiconductor gas sensors based on the prepared $\mathrm{CuO}$ nanoribbons and investigated their sensing properties towards $\mathrm{HCHO}$ and ethanol gas. At the same time, the effects of noble metals on the sensing performance of the p-type semiconductor sensor were also examined. As a comparison, commercial $\mathrm{CuO}$ powder and the as-synthesized nanoplates were also tested.

Fig. 5(a) shows typical isothermal response curves of $\mathrm{CuO}$-based sensors when cycled with increasing $\mathrm{HCHO}$ vapour concentrations from 5 to $500 \mathrm{ppm}$ in ambient air. It can be seen that the resistance of commercial powder (black curve) showed almost no changes over the whole concentration range, indicating that the $\mathrm{CuO}$ commercial powder is insensitive to $\mathrm{HCHO}$. In contrast, the resistance of the as-synthesized nanoplates increased even when the concentration of $\mathrm{HCHO}$ was very low (5 ppm), and it continued to increase gradually with increasing vapour concentration. It should be noted that the trend in the changing resistance of the p-type semiconductor sensor with the concentration of the reducing gas was completely opposite to that of an n-type sensor, implying that their sensing mechanisms are different. The major charge carriers are holes and electrons for $\mathrm{p}$-type and n-type semiconductors, respectively. Upon exposure to a reducing gas, the density of p-type charge carriers (positive holes) would decrease due to surface adsorption and chemical reaction between the gas and oxide sensor (electron donation), resulting in an increase of its resistance, which is opposite to what is seen with the n-type semiconductor gas sensors. ${ }^{8,21}$ It was striking that all three nanoribbon-based sensors with or without noble metal additives show much better response to $\mathrm{HCHO}$ at any given gas concentration than the nanoplates or the commercial powders. Their resistance underwent a dramatic increase on the injection of $\mathrm{HCHO}$ and then rapidly recovered after the test gas was released. 

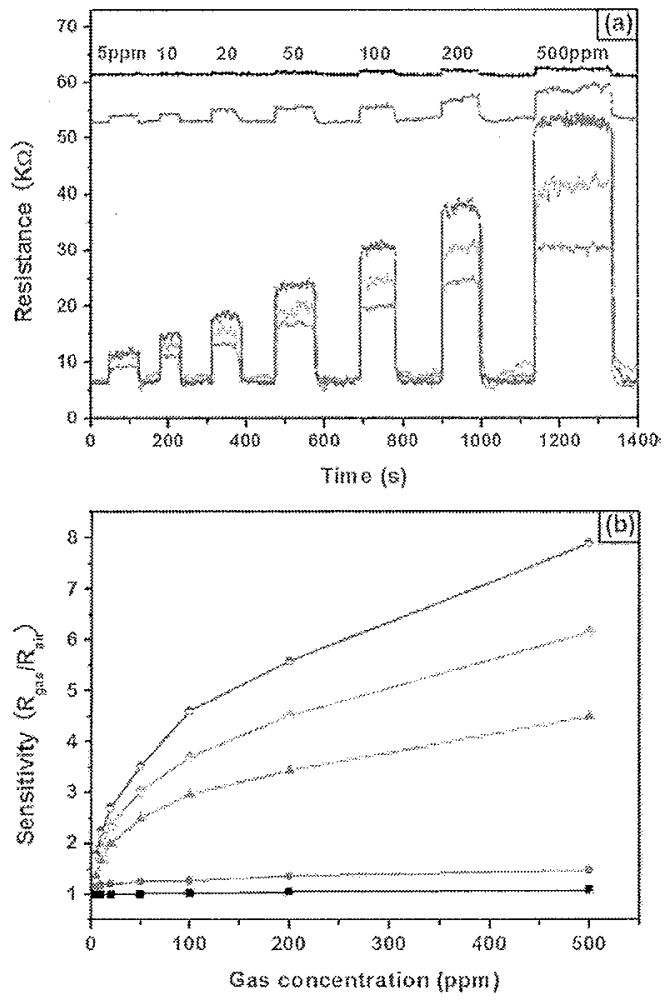

Fig. 5 (a) Typical response curves of the CuO-based sensors during cycling between increasing concentration of $\mathrm{HCHO}$ and ambient air; (b) sensitivity versus $\mathrm{HCHO}$ concentration. The black, violet, red, green and blue curves denote commercial powder, nanoplates, pristine nanoribbons, $\mathrm{Au}-\mathrm{CuO}$ nanoribbons and $\mathrm{Pt}-\mathrm{CuO}$ nanoribbons, respectively.

The response time and recovery time (defined as the time required to reach $90 \%$ of the final equilibrium value) were only 2-4 and 3-7 s, respectively. This result indicated that the nanoribbon-based sensors have good reversibility. Compared to other reported $\mathrm{HCHO}$ sensors ${ }^{29,30}$ the $\mathrm{CuO}$ nanoribbons offered the fastest response and recovery capacities. The detection limit of the $\mathrm{CuO}$ nanoribbon-based sensor towards $\mathrm{HCHO}$ can be as low as 5 ppm. Furthermore, among the three nanoribbon-based sensors, the response amplitudes of the $\mathrm{Pt}-\mathrm{CuO}$ nanoribbons (blue curve) and the $\mathrm{Au}-\mathrm{CuO}$ nanoribbons (green curve) are always higher than that of the pristine $\mathrm{CuO}$ nanoribbons (red curve) at any gas concentration, indicating a promotion effect of the noble metal nanoparticles due to their catalytic capacity. ${ }^{19,20}$ Fig. $5(\mathrm{~b})$ shows the correlation between the sensitivity of the five CuO-based sensors and the concentration of HCHO. Here the gas sensitivity was defined as the ratio of the stationary electrical resistance of each element in the test gas $\left(R_{\mathrm{gas}}\right)$ and in air $\left(R_{\mathrm{air}}\right)$, i.e., $S=R_{\mathrm{gas}} / R_{\mathrm{air}}$. The figure clearly illustrates that the $\mathrm{CuO}$ bulk powders have no sensitivity to $\mathrm{HCHO}$ even at the high concentration of $500 \mathrm{ppm}$, while the nanoplates showed very low sensitivity to $\mathrm{HCHO}$. However, all the $\mathrm{CuO}$ nanoribbon-based sensors displayed high sensitivity to HCHO in the concentration range from 5 to $500 \mathrm{ppm}$. Their sensitivities took on an exponential rate of increase at first (below $100 \mathrm{ppm}$ ), which then changed to a linear increase in the range of 100-500
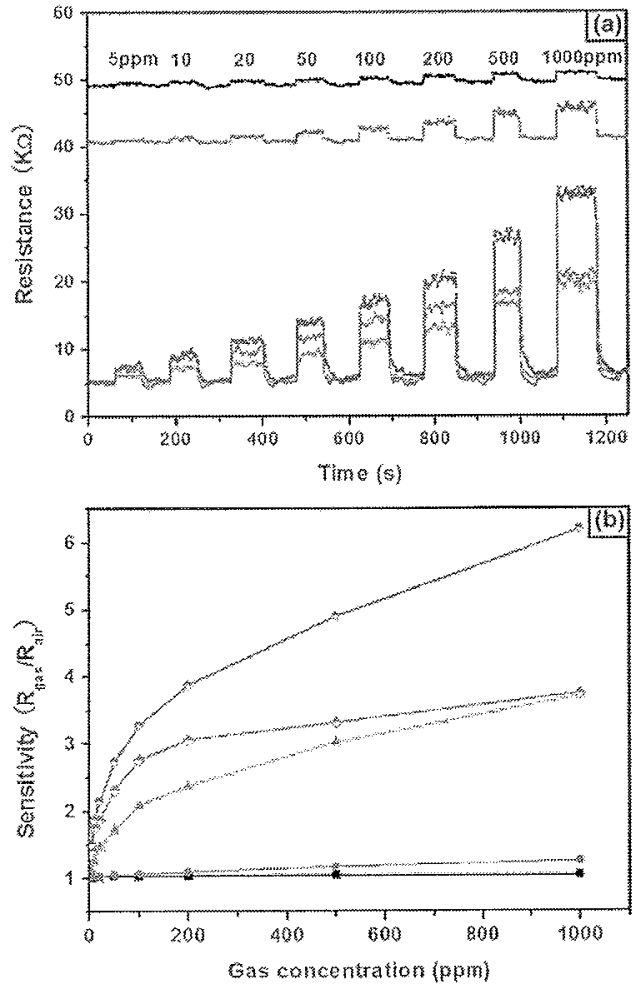

Fig. 6 (a) Typical response curves of the CuO-based sensors on cycling between increasing concentration of ethanol and ambient air at $200{ }^{\circ} \mathrm{C}$; (b) sensitivity versus ethanol concentration. The black, violet, red, green and blue curve denotes commercial powder, nanoplates, pristine nanoribbons, $\mathrm{Au}-\mathrm{CuO}$ nanoribbons, and $\mathrm{Pt}-\mathrm{CuO}$ nanoribbons, respectively.

ppm. As a whole, the sensitivity of CuO-based sensors to HCHO increased in the following order: bulk powder $<$ nanoplates $\ll$ pristine nanoribbons $<$ Au-nanoribbons $<$ Pt-nanribbons. The Pt-doped $\mathrm{CuO}$ nanoribbons exhibited the best gas sensing performance.

The sensing performance of the CuO-based gas sensors to ethanol in the concentration range of $5-1000 \mathrm{ppm}$ is displayed in Fig. 6. Similar to the sensing test results on $\mathrm{HCHO}$, the resistances of all the sensors increased to different extents on exposure to ethanol yapour, and then recovered on the release of the test gas. The response and sensitivity of all the nanoribbon-based sensors were much better than those of the nanoplates and bulk powder, and their response and recovery times were 3-6 and 4-9 s, respectively. Compared to a recent report ${ }^{31}$ on the sensing properties of $\mathrm{CuO}$ nanorods to ethanol, which showed a sensitivity of about 2 in an atmosphere of $2000 \mathrm{ppm}$ ethanol at a working temperature of $300{ }^{\circ} \mathrm{C}$, the sensitivity of our pristine $\mathrm{CuO}$ nanoribbons was at least double at much lower concentration $(1000 \mathrm{ppm})$ and working temperature $\left(200^{\circ} \mathrm{C}\right)$. This result may be attributed to the unique geometry of the $\mathrm{CuO}$ nanoribbons. Nanoribbons are thought to have a higher surface-to-volume ratio, and low surface-contact resistance, as well as providing a pathway for free carriers, allowing them to cross the bulk of the ribbons along the axis, much as in a field effect transistor channel. ${ }^{32}$ The surface area of $\mathrm{CuO}$ nanoribbons 
was measured to be $126.4 \mathrm{~m}^{2} \mathrm{~g}^{-1}$ by using a Quanta Chrome Nova 1000 Gas Sorption Analyzer. High surface area of $\mathrm{CuO}$ of the nanoribbons may be another important factor in allowing them to adsorb a maximum amount of gas molecules. It should be noted that the relatively low operation temperature helps to decrease the consumption of energy, and can improve the suitability of the sensor in some particular situations. Furthermore, the sensing performance can be enhanced by functionalization with a small amount of $\mathrm{Au}$ and Pt nanoparticles. For example, the sensitivity of $\mathrm{Au}-\mathrm{CuO}$ nanoribbons improved exponentially in the low concentration range, while the sensitivity of the $\mathrm{Pt}-\mathrm{CuO}$ nanoribbons distinctly increased over a wide concentration range.

We noticed that the Pt additive always showed a better effect to the sensing enhancement than Au. This may be caused by differences in their catalytic activity. ${ }^{8}$ At the same time, the $\mathrm{CuO}$ nanoribbon-based sensors always showed higher sensitivity to HCHO than to ethanol. This discrepancy may be due to their different surface reaction mechanisms. It has been reported that ethanol is oxidized to $\mathrm{CO}_{2}$ on the surface of an oxide sensor through a series of intermediate steps including the formation of ethoxy groups and acetaldehyde. Therefore, it can be deduced that formaldehyde has a more active surface reaction than ethanol on $\mathrm{CuO}$ sensors, and thus results in higher sensitivity and a quicker response time.

\section{Conclusions}

In conclusion, the synthesis of $\mathrm{CuO}$ nanoribbons and their functionalization with nanosize noble metal particles such as $\mathrm{Au}$ and Pt were achieved by a wet chemical method. The as-prepared $\mathrm{CuO}$ nanoribbons contain nanorings and nanoloops. HRTEM and SAED analysis confirmed that $\mathrm{CuO}$ nanoribbons, nanorings and nanoloops all grow along the [010] direction. The gas sensing properties towards $\mathrm{HCHO}$ and ethanol of the resultant materials have been investigated, demonstrating that $\mathrm{CuO}$ nanoribbons have quicker response and higher sensitivity than those of other counterparts to both $\mathrm{HCHO}$ and ethanol at a low operating temperature. Furthermore, functionalizing the $\mathrm{CuO}$ nanoribbons with Pt or Au nanoparticles leads to a remarkable enhancement of their gas sensing performance.

\section{Acknowledgements}

We thank the Australian Research Council (ARC) for financial support through the ARC Discovery Project (DP0559891)

\section{References}

1 X. Duan, Y. Huang, Y. Cui, J. Wang and C. M. Lieber, Nature, 2001, 409, 66-69.

2 D. M. Whang, J. Song, Y. Ma and C. M. Lieber, Nano Lett, 2003, 3, 1255-1259.

3 Y. N. Xia, P. D. Yang, Y. G. Sun, Y. Y. Wu, B. Mayers, B. Gates, Y. D. Yin, F. Kim and H. Q. Yan, Adv. Mater., 2003, 15, 353-389.

4 Z. W. Pan, Z. R. Dai and Z. L. Wang, Science, 2001, 291, 1947-1949.

5 J. Polleux, A. Gurlo, N. Barsan, U. Weimar, M. Antonietti and M. M. Niederberger, Angew. Chen., Int. Ed., 2006, 45, $261-265$.

6 Y. Cui, Q. Q. Wei, H. K. Park and C. M. Lieber, Science, 2001, 293, 1289-1292.

7 A. Kolmakov and M. Moskovits, Annu. Rev. Mater. Res., 2004, 34 $151-180$.

8 A. Gurlo and R. Riedel, Angew. Chem., Int. Ed., 2007, 46, 3826-3848.

9 M. C. Mcalpine, H. Ahmad, D. Wang and J. R. Heath, Nat. Mater., $2007,6,379-384$

10 M. Law, H. Kind, B. Messer, F. Kim and P. D. Yang, Angew. Chem. Int. Ed., 2002, 41, 2405-2408.

11 D. Zhang, Z. Liu, C. Li, T. Tang, X. Liu, S. Han, B. Lei and C. Zhou, Nano Lett., 2004, 4, 1919-1924.

12 J. Chen, L. N. Xu, W. Y. Li and X. L. Gou, Adv. Mater, 2005, 17, $582-586$.

13 I. Raible, M. Burghard, U. Schlecht, A. Yasuda and T. Vossmeyer, Sens. Actuators, B, 2005, 106, 730-735.

14 Q. Wan, Q. H. Li, Y. J. Chen, T. H. Wang, X. L. He, J. P. Li and C. L. Lin, Appl. Phys. Lett., 2004, 84, 3654-3656.

15 C. A. Grimes, J. Mater. Chem., 2007, 17, 1451-1457.

16 E. Comini, G. Faglia, G. Sberveglieri, Z. Pan and Z. L. Wang, Appl. Phys. Lett., 2002, 81, 1869-1871.

17 J. Liu, X. Wang, Q. Peng and Y. D. Li, Adv. Mater, 2005, 17 , $764-767$.

18 A. Kolmakov, D. O. Klenov, Y. Lilach, S. Stemmer and M. Moskovits, Nano Leit., 2005, 5, 667-673.

19 C. Canevali, C. M. Mari, M. Mattoni, F. Morazzoni, L. Nodari, R. Ruffo, U. Russo and R. Scotti, J. Phys. Chem. B, 2005, 109, $7195-7202$

20 O. Safonova, I. Bezverkhy, P. Fabrichnyi, M. Rumyantseva and A. Gaskov, J. Mater. Chem., 2002, 12, 1174-1178.

21 J. Zhang, J. Liu, Q. Peng, X. Wang and Y. D. Li, Chem. Mater., 2006, 18, 867-871.

22 L. Rout, T. K. Sen and T. Punniyamurthy, Angew. Chem., Int. Ed., 2007, 46, 5583-5586.

23 P. Poizot, S. Laruelle, S. Grugeon, L. Dupont and J. M. Tarascon, Nature, 2000, 407, 496-499.

24 B. Liu and H. C. Zeng. J. Am. Chem. Soc., 2004, 126, 8124-8125.

25 X. Jiang, T. Herricks and Y. N. Xia, Nano Lett, 2002, 2, 1333-1338.

26 X. Wen, Y. Xie, C. L. Choi, K. C. Wan, X. Li and S. H. Yang, Langmiir, 2005, 21, 4729-4737.

$27 \mathrm{M}$. Cao, C. Hu, Y. Wang, Y. Guo, C. Guo and E. Wang, Chem. Commun., 2003, 1884-1885.

$28 \mathrm{X}$. Wang, G. Xi, S. Xiong, Y. Liu, B. Xi, W. Yu and Y. Qian, Cryst. Growth Des., 2007, 7,930-934.

29 J. Xu, X. Jia, X. Lou, G. Xi, J. Han and Q. Gao, Sens. Actuators, B, $2007,120,694-699$.

30 C. Lee, C. Chiang, Y. Wang and R. Ma, Sens. Actuators, B, 2007, 122, 503-510.

31 C. Wang, X. Q. Fu, X. Y. Xue, Y. G. Wang and T. H. Wang, Nanoteclnology, 2007, 18, 145506.

32 Z. L. Wang, Annu. Rev. Phys. Chem., 2004, 55, 159-196. 